\title{
La construcción del significado psicológico del concepto profesor o profesora por parte de grupos universitarios de estudiantes de pedagogía
}

\section{The Construction of the Psychological Meaning of the Concept of Professor by University Students of Pedagogy}

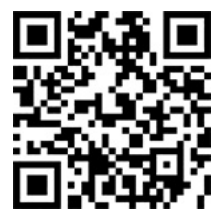

\author{
Cristián Manuel Aguilar-Correa ${ }^{1}$ \\ Universidad Católica del Maule \\ Talca, Chile \\ caguilar@ucm.cl \\ http://orcid.org/0000-0002-2639-7216
}

Recibido 30 de diciembre de 2015 • Corregido 29 de octubre de 2016 • Aceptado 5 de diciembre de 2016

\begin{abstract}
Resumen: La investigación tuvo por objetivo identificar las redes semánticas que propiciarán el análisis de la construcción del significado psicológico del concepto profesor o profesora, por parte de grupos universitarios de estudiantes en su primer año de pedagogía. Para llevar a cabo este estudio, utilizamos la técnica de redes semánticas naturales (Valdez, 1998). El instrumento se aplicó a una muestra no probabilística intencionada de 409 estudiantes de las Facultades de Ciencias de la Educación, Facultad de Ciencias Básicas y Facultad de Filosofía y Religión de la Universidad Católica del Maule (Chile). Los resultados dan cuenta de elementos comunes en las representaciones psicológicas de los grupos en estudio, pero significados diferenciados en los núcleos de las redes conceptuales surgidas, ello, según la carrera, el nivel educativo al cual se vinculan como futuros maestros y maestras, y los escenarios socioculturales en los que se teje su profesión.
\end{abstract}

Palabras claves: Significado psicológico; redes semánticas naturales; docente; estudiantes de pedagogía.

Abstract: The research aimed to identify the semantic networks that will foster the analysis of the construction of the psychological meaning of the concept teacher, by university students in their first year of Pedagogy. To carry out this study, we use the technique of Natural Semantic Networks (Valdez, 1998). The instrument was applied to an intentional non-probabilistic sample of 409 students from the Facultad de Ciencias de la Educación [Faculty of Education Sciences], Facultad de Ciencias Básicas [Faculty of Basic Sciences], and Facultad de Filosofía y Religión [Faculty of Philosophy and Religion] of the Universidad Católica del Maule (Chile). The results show common elements in psychological representations of the studied groups, but meanings differentiated in the nuclei of the emerging conceptual networks, and this, according to the career, the educational level they are tied to as future teachers, and the socio-cultural scenarios in which their profession is interwoven.

Keywords: Psychological meaning, natural semantic networks, professor, pedagogy students.

\footnotetext{
1 Profesor de Educación General Básica, Magister en Educación de las Ciencias y Dr. en Didáctica de las Ciencias Experimentales por la Universidad Complutense de Madrid. Posee más de 10 años de experiencia educativa en el sistema público escolar chileno. En el último tiempo ha trabajado formando el futuro profesorado, inicialmente en la Escuela de Educación de la Universidad Católica del Norte (Antofagasta-Chile) y en la actualidad en la Facultad de Ciencias de la Educación de la Universidad Católica del Maule-Chile. Su trabajo investigativo, lo ha focalizado hacia temáticas de formación inicial docente (FID), didáctica de las ciencias experimentales y educación ambiental.
} 
doi: http://dx.doi.org/10.15359/ree.21-1.13

URL: http://www.una.ac.cr/educare

CORREO: educare@una.cr

\section{Introducción}

La multiplicidad de investigaciones en las últimas décadas, de mano de la psicología cognitiva, nos ha abierto una serie de puertas para comprender el conocimiento humano. Las preguntas sobre cómo seleccionamos, organizamos, procesamos y damos significado a la información han sido las interrogantes fundamentales hacia donde se han enfocado los propósitos investigativos.

Trabajos clásicos como los de Minsky (1975), Rumelhart (1975) y Winograd (1975) sostienen que el conocimiento estaría organizado a partir de redes conceptuales. Serían, estas últimas (a través de procesos reconstructivos de la memoria), los elementos que permiten a los sujetos tener un plan de acción, así como una evaluación subjetiva de los eventos, acciones u objetos respecto de los acontecimientos ambientales (Ormrod, 2010). Por lo tanto, en esta dialéctica, entre individuo y ambiente se van construyendo elementos de significado que van configurando, de una u otra forma, la realidad de los sujetos y situándolos históricamente (Bourdieu, 2012).

Ahora bien, en el ámbito educativo, tener en cuenta los aspectos declarados precedentemente representa todo un desafío formativo. Comprender los significados que posee el profesorado respecto de lo que implica ser profesor o profesora es un factor relevante acerca de lo que ocurrirá en la enseñanza. El pensamiento del personal docente, y en concreto, sus teorías, ideas, creencias y modelos guían su labor y condicionan, de manera significativa, los acontecimientos que ocurrirán en el aula (García-Carmona, Vásquez, Manassero, 2011). Por tanto, comprender la trayectoria de un saber sabio hacia un saber enseñado (Chevallard, 2000) no solo requiere de una reestructuración del armazón didáctico en su totalidad, sino, también, de una reestructuración epistemológica que admite un enorme desafío para las universidades que hoy forman docentes.

Con estos propósitos en mente, quisimos llevar a cabo esta investigación. Nuestro objetivo era poder identificar las redes semánticas naturales que propiciarán el análisis de la construcción del significado psicológico del concepto profesor o profesora, por parte de grupos universitarios de estudiantes de pedagogía.

El estudio lo llevamos a cabo al interior de la Universidad Católica del Maule (Chile), en las facultades de Ciencias de la Educación, Ciencias Básicas y Ciencias Filosóficas y Religiosas. Todas ellas formadoras de docentes con distintas especialidades y niveles educativos.

Para poder realizar el estudio, utilizamos la técnica de redes semánticas naturales (RSN), propuesta por Valdez (1998). El instrumento se aplicó a una muestra de 409 estudiantes de las diez carreras de pedagogía con que cuenta, en la actualidad, esta casa de estudios superiores. 
doi: http://dx.doi.org/10.15359/ree.21-1.13

URL: http://www.una.ac.cr/educare

CORREO: educare@una.cr

\section{Marco teórico}

Para Morin (2007, p. 154) "conocer es producir una traducción de las realidades del mundo exterior ... Somos coproductores del objeto que conocemos; cooperamos con el mundo exterior y es esa coproducción la que nos da la objetividad del objeto". Por su parte, Maturana y Varela, (2003) sostienen que:

El conocer no se lo puede tomar como si hubiera hechos u objetos allá afuera, que uno capta y se los mete a la cabeza. La experiencia de cualquier cosa allá afuera es validada de una manera particular por la estructura humana que hace posible la cosa que surge de la descripción. (p. 3)

Diversos estudios (Marshall, 1995; McKoon y Ratcliff, 1986; Rumelhart, 1984) indican que los seres humanos utilizamos esquemas para organizar el conocimiento. Piaget e Inhelder (2007) sostienen que estos esquemas son los que nos permiten simbolizar los objetos y las ideas de nuestro mundo; organizadas en complejas representaciones que controlarían la codificación, el almacenamiento, la recuperación y la significación de la información.

Ahora bien, ¿qué entendemos por concepto? De acuerdo con Ausubel (2009)“los conceptos se pueden definir como objetos, eventos, situaciones o propiedades que poseen unos atributos característicos comunes y que están designados por el mismo símbolo o signo" (p. 26).

Por su parte, Pattee (1973) indica que los conceptos establecen relaciones de restricción mutua, cuya especificidad determina que cada elemento tenga una significación específica, no hay significados per se de cada concepto, sino que, más bien, estos son el resultado de un juego de interacciones entre cada uno de los elementos intervinientes.

Finalmente, Hofstadter (1982) sostiene que un concepto está determinado por la manera en que este se conecta con otros conceptos. Por lo tanto, la propiedad de ser un concepto es una propiedad de conexión, una cualidad que está ligada a la pertenencia a un cierto tipo de redes.

Con respecto a los modelos de organización de la información, asumen una serie de supuestos para explicar la construcción del significado, dentro de los cuales, según Rumelhart (1984) y Norman (1987), los más importantes serían la existencia de grupos de símbolos conectados entre sí, la existencia de una estructura de relaciones entre los elementos interactuantes y dicha estructura se organizaría a través de niveles jerárquicos.

Quillian (1968, 1969); Rips, Shoben, Smith (1973); Collins y Loftus (1975); Anderson (1983); Figueroa (1980); Norman (1987) y Vygotski (2009) han sido quienes más han intentado estudiar y explicar el fenómeno del significado. 
doi: http://dx.doi.org/10.15359/ree.21-1.13

URL: http://www.una.ac.cr/educare

CORREO: educare@una.cr

Ahora bien, ¿cómo construimos significado los individuos? Vygotski (2009) reconoce la existencia de un mundo interno que los sujetos construimos a partir de un proceso de internalización de un mundo externo; que nos define y caracteriza constantemente. Esta construcción se halla en las distintas conexiones que el ser humano genera a partir de los signos, que cumplen un papel primordial en la comprensión y construcción de los significados.

Vygotski sostiene que, si los signos se encuentran en la cultura, los significados son parte consustancial de ella. En consecuencia, para el autor, los significados se construyen a través de la internalización de los procesos psicológicos superiores, cuyo valor radica en la capacidad de crear estímulos artificiales que pasan finalmente a ser causas inmediatas de nuestras conductas (Vygotski, 2009).

Tal como lo señalan Maturana y Varela, (2003, p. 13) "Este encadenamiento entre acción y experiencia, esta inseparabilidad entre ser de una manera particular y cómo el mundo nos aparece, nos dice que todo acto de conocer trae un mundo a la mano ... Todo hacer es conocer y todo conocer es hacer". "No hay objeto si no es con respecto a un sujeto (que observa, aísla, define, piensa), y no hay sujeto sino es con respecto a un ambiente objetivo (que le permite reconocerse, definirse, pensarse, ... pero también de existir)" (Morin, 2007, p. 67). Por lo tanto, en esta dialéctica de reciprocidad y de retroactividad, los individuos vamos organizando las ideas, interpretando el mundo, situándonos históricamente en él (Bourdieu, 2012) y otorgándole sentido. En efecto, atribuir valor a un concepto, a un objeto, a un signo implica ponerlo en estrecha interacción con otros elementos y con el medio circundante (Vera-Noriega, Pimentel y Batista, 2005).

\section{Las redes semánticas naturales}

El modelo de RSN intenta dar una explicación acerca de cómo ocurre la construcción del conocimiento respecto de las diferentes relaciones que se dan entre familias de conceptos (Figueroa 1980).

Para las RSN, la información almacenada en la memoria está organizada en nodos conceptuales que, en conjunto, producen significados de organización cognoscitiva, cargados de elementos figurativos. Estos crean un código subjetivo de reacción y reflejan, de esta manera, la imagen simbólica que los sujetos nos hacemos del mundo que transitamos.

Esta técnica nos ofrece una metodología práctica de trabajo con el fin de poder vislumbrar cómo los sujetos organizan el conocimiento en su estructura cognitiva (Ausubel, 2009; Novak, 1990) y, cómo a partir de esta internalización (Vygotski, 2009) de significantes, el significado es construido desde un escenario cargado de entidades psicológicas individuales, matizadas por un potente medio cultural (Marcelo, 1999). 
doi: http://dx.doi.org/10.15359/ree.21-1.13

URL: http://www.una.ac.cr/educare

CORREO: educare@una.cr

Desde el punto de vista de nuestra investigación, la técnica fue desarrollada con estudiantes que inician su proceso formativo como docentes y que cursan alguna de las 10 carreras pedagógicas impartidas al interior de la Universidad Católica del Maule.

Por un lado, nos interesó poder identificar las RSN que construye dicho estudiantado, propiciando con ello el análisis del significado psicológico. Y, por otro, poder identificar si estas redes conceptuales construidas (en función de la naturaleza de la carrera y su facultad) obedecen más a cuestiones científico-formales o bien se han ido configurando en representaciones sociales compartidas entre grupos de pertenencia (García-Villanueva, De la Rosa-Acosta y Castillo-Valdés, 2012).

Finalmente, es importante indicar que, desde el año 2014, la Universidad Católica del Maule inició la ejecución de un proyecto de Plan de Mejoramiento Institucional (PMI), focalizado hacia la innovación pedagógica en la formación inicial docente (FID), en procura de fortalecer la calidad del desempeño pedagógico, disciplinar y profesional de cada estudiante que cursa alguna carrera educativa al interior de esta, con el objeto de impactar positivamente en los territorios escolares y, de manera especial, en los entornos más vulnerables; contexto en el cual se enmarca esta investigación.

\section{Metodología}

\section{Participantes}

La muestra, de tipo no probabilística intencionada, dada por el número de estudiantes presentes al momento de la aplicación del instrumento, estuvo compuesta por 409 participantes, de un universo de 522 sujetos. Este valor equivale al 78\% del total de estudiantes de primer año de todas las carreras de pedagogía que imparte la Universidad.

De la muestra de estudiantes participantes 288 fueron mujeres, lo que equivale al $70 \%$ del total y 121 hombres que representan el 30\% restante.

Cabe mencionar que el estudiantado se encontraba repartido en tres facultades, a saber: Facultad de Ciencias de la Educación: 32 estudiantes de la Carrera de Educación Parvularia, 50 estudiantes de la Carrera de Pedagogía en Educación Especial, 47 estudiantes de la Carrera de Pedagogía en Educación General Básica con mención (Matemática, Lenguaje y Comunicación, Historia y Geografía y Ciencias Naturales), 46 de Pedagogía en Inglés, 80 pertenecientes a la Carrera de Pedagogía en Educación Física, 40 pertenecientes a la Carrera de Pedagogía en Lengua Castellana y Comunicación y, por último, 35 estudiantes de Pedagogía en Educación General Básica. 
doi: http://dx.doi.org/10.15359/ree.21-1.13

URL: http://www.una.ac.cr/educare

CORREO: educare@una.cr

Por su parte, de la Facultad de Ciencias Básicas participaron 38 estudiantes de Pedagogía en Matemática y Computación y 34 de Pedagogía en Ciencias con mención (Física, Química y Biología).

Finalmente, de la Facultad de Ciencias Filosóficas y Religiosas respondieron el instrumento 7 estudiantes, pertenecientes a la Carrera de Pedagogía en Religión y Filosofía.

\section{Diseño}

El diseño utilizado fue transseccional descriptivo-comparativo, fundamentado desde un método mixto, a través de la técnica de RSN.

\section{Instrumento}

Se empleó la técnica de RSN, que intenta dar una explicación acerca de cómo ocurre la construcción de los significados en los individuos. El trabajo empírico lo desarrollamos siguiendo las indicaciones de su autor (Valdez, 1998).

La idea es que los sujetos participantes definan, libre y espontáneamente, con la mayor precisión posible, un concepto nodal dado (en nuestro caso el reactivo fue profesor). Para ello, deben utilizar un mínimo de cinco palabras (no frases), que posteriormente y de manera individual, deben jerarquizar de acuerdo con la importancia o cercanía que consideren tienen sus palabras respecto del concepto nodal otorgado. Asignan el número 1 a la palabra más cercana, el 2 a la que sigue y así sucesivamente hasta terminar con el número 5. Luego, los datos son procesados siguiendo las pautas establecidas por los estudios mencionados anteriormente.

\section{Procesamiento de los datos}

En primer lugar, se obtiene el Valor J. Este valor es el resultado de la suma total de las palabras definidas por el estudiantado respecto del concepto nodal dado. En el fondo, este cuociente es un indicador de la riqueza semántica de la red. A mayor cantidad de palabras obtenidas, mayor será la riqueza de esta, por el contario, a menor número de palabras, menor riqueza de la red (Valdez, 1998).

Seguidamente se obtiene el conjunto SAM, valor correspondiente al grupo de las diez palabras con el valor $M$ más elevado, entendiendo como tal el que se obtiene a partir de la multiplicación del valor de la frecuencia (asignado por estudiantes a cada concepto) por el valor semántico (Valdez, 1998). Este es un dato importante, ya que nos revela cuáles fueron aquellos 
doi: http://dx.doi.org/10.15359/ree.21-1.13

URL: http://www.una.ac.cr/educare

CORREO: educare@una.cr

conceptos nucleares de la red. En el fondo, este indicador es el centro mismo del significado que tiene el concepto para el estudiantado.

Finalmente, obtenemos el valor FMG, que es un indicador (en porcentaje) de la distancia semántica que hay entre las diferentes palabras que conforman el conjunto SAM (Valdez, 1998). Este valor es obtenido para todas las palabras que definió el estudiantado con respecto al conjunto SAM. Se obtiene mediante una regla de tres simple, tomando como inicio la palabra con el valor M mayor, la cual representa el $100 \%$.

\section{Resultados}

Para una mejor claridad en la presentación de los resultados, utilizamos la siguiente estrategia. En primer lugar, se muestra una figura que detalla el conjunto SAM para cada una de las 10 carreras participantes, según facultad a la que pertenecen, naturaleza de esta y nivel educativo al cual proyectan su acción educativa. Esencialmente, lo que aquí se puntualiza está referido a visibilizar el núcleo conceptual figurativo del reactivo (Profesor) y la distancia semántica entre las palabras declaradas (valores M total, VMT y valores FMG). En segundo término, se presenta una figura con un gráfico radial, que nos muestra la configuración de la red conceptual definida (por carrera), cuyo valor nos indica detalladamente las distancias semánticas en las agrupaciones de palabras generadas.

\section{Facultad de Ciencias de la Educación}

Los principales conceptos que configuran la red semántica definida por el alumnado de Pedagogía en Educación General Básica, respecto del nodo profesor, se agrupan como se observa en las Figuras 1 y 2.

El núcleo de la red está dado por el concepto troncal Guía. Le sigue el concepto Educador/a, con un peso semántico del 87\%, también figura el concepto de Mediador/a, con una puntuación de 52 VMT y un porcentaje del 60\%. Enseñanza con 41 de valor M total y porcentaje del $41 \%$. Con valor muy similar, respecto de este último, aparece el concepto de Autoridad, con valor M de 32 y FMG del 36\%. Por su parte, también surgen los conceptos de Ayudante, Modelo y Sabio/a, con 26, 25 y 23 de valor M total y porcentajes del 29\%, 28\% y $26 \%$, respectivamente. Finalmente, con un peso semántico entre el $15 \%$ y el $20 \%$ figuran los conceptos de Familia y Motivación. La riqueza semántica de la red estuvo compuesta por u total de 20 definidoras. 
doi: http://dx.doi.org/10.15359/ree.21-1.13

URL: http://www.una.ac.cr/educare

CORREO: educare@una.cr

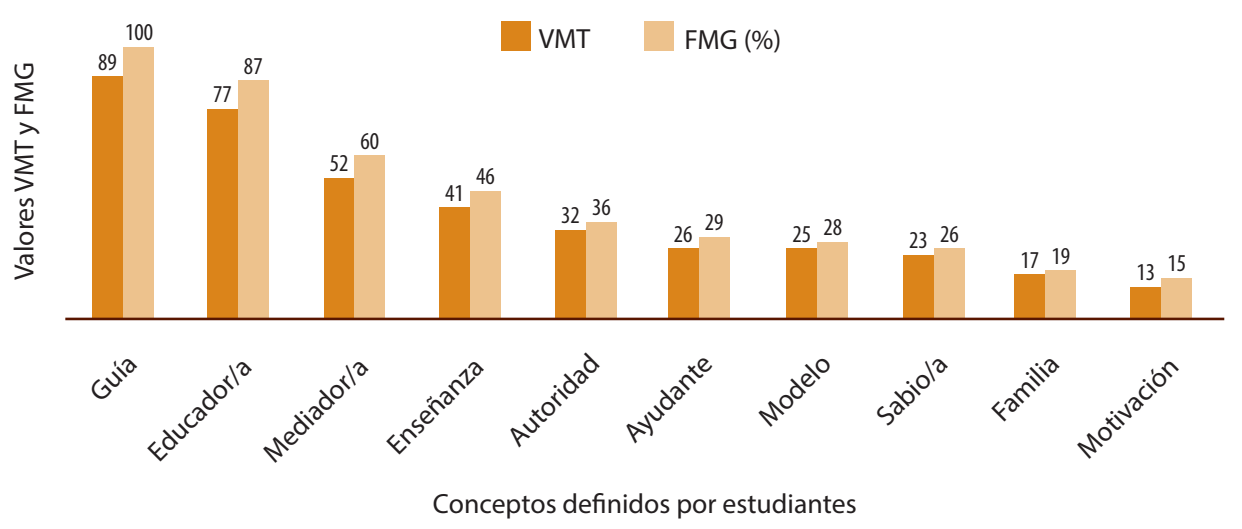

Figura 1: Conjunto SAM estudiantes de Pedagogía en Educación General Básica.

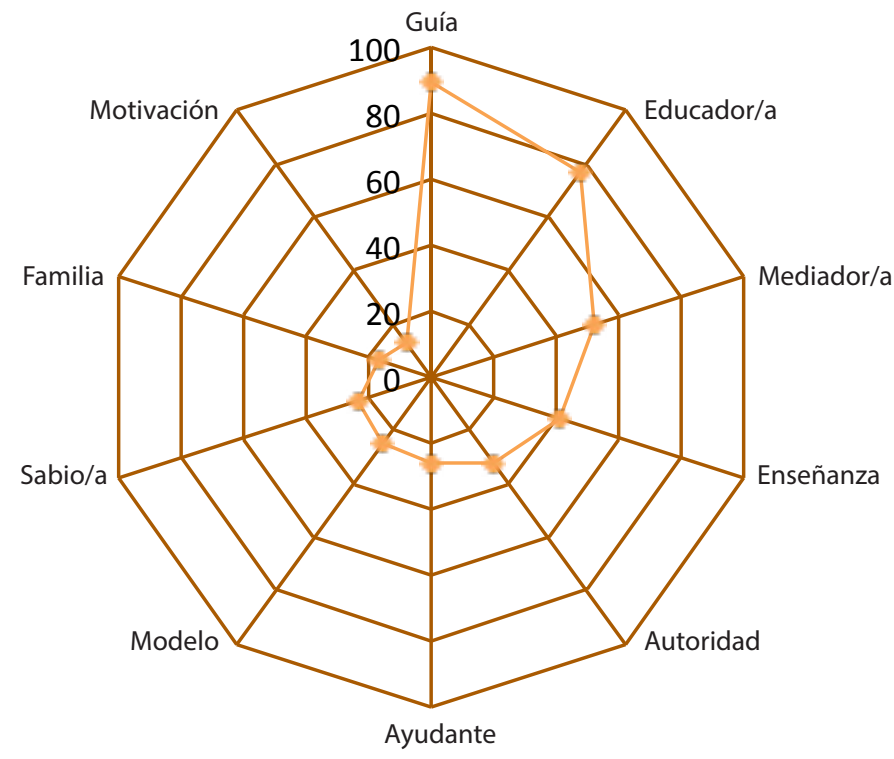

Figura 2: Núcleo de la red semántica estudiantes de Pedagogía en Educación General Básica.

En cuanto a la red de significados, desarrollada por estudiantes de la carrera de Pedagogía en Educación General Básica con mención (ver Figuras 3 y 4), el mayor peso semántico fue para el concepto Guía, VMT de 163, y FMG del 100\%. Posteriormente, figura el concepto de Educador/a, con VMT de 91 y porcentaje del 56\%. También, hay resultados significativos para los conceptos Mediador/a y Modelo. El primero con VMT de 63 y FMG del $24 \%$ y, el segundo con un valor M total de 56 y un porcentaje del $34 \%$. 
doi: http://dx.doi.org/10.15359/ree.21-1.13

URL: http://www.una.ac.cr/educare

Por otro lado, hay un conjunto de conceptos que tienen un peso semántico entre un 19\% y 26\%, ellos son: Líder, Cercano/a y Ayuda. Por último, figura un grupo de tres conceptos alejados y que registran valores FMG cercanos al 10\%. Estos conceptos son: Orientador/a, Facilitador/a y Constructor/a. Cabe señalar que la riqueza semántica de la red estuvo compuesta por un total de 32 definidoras.

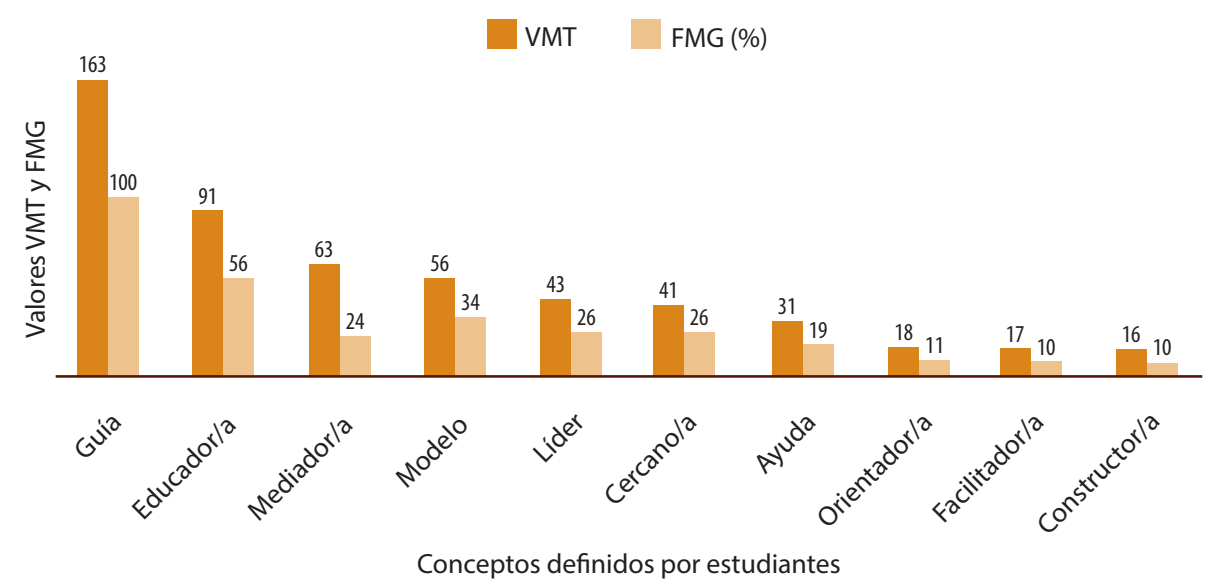

Figura 3: Conjunto SAM estudiantes de Pedagogía en Educación General Básica con mención.

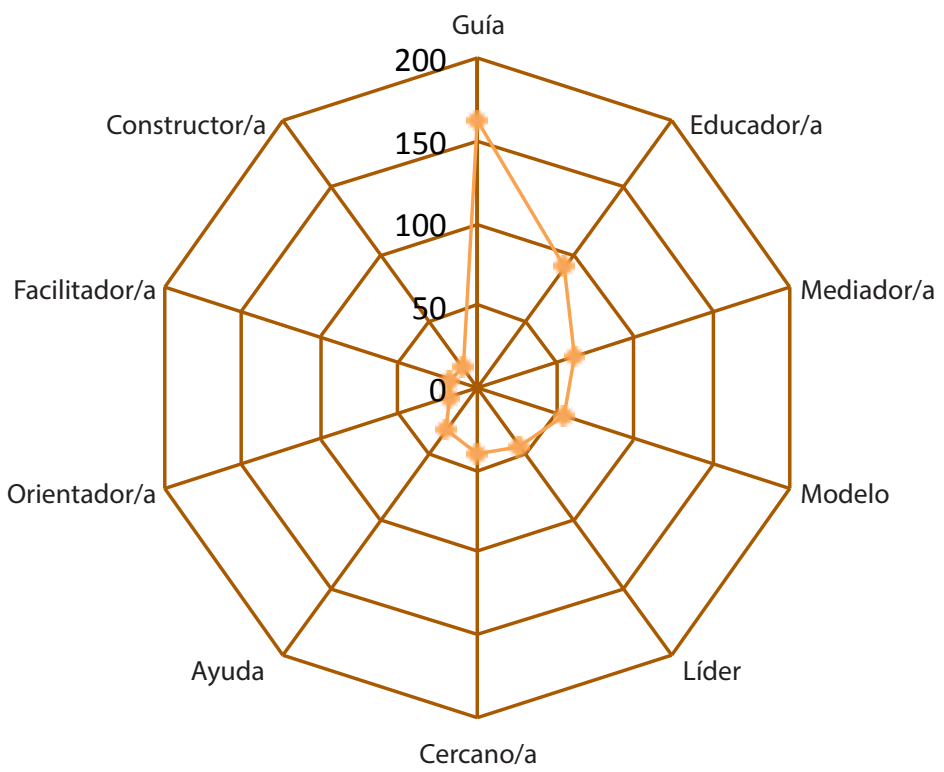

Figura 4: Núcleo de la red semántica estudiantes de Pedagogía en Educación General Básica con mención. 
doi: http://dx.doi.org/10.15359/ree.21-1.13

URL: http://www.una.ac.cr/educare

CORREO: educare@una.cr

En cuanto al significado psicológico del concepto Profesor/a, para las alumnas de la Carrera de Educación Parvularia (ver Figuras 5 y 6), el núcleo de la red quedó compuesto por la palabra Educador. También hay valores significativos para los conceptos de Enseñanza, Vocación y Guía, con VMT de 47, 39, 34 y porcentajes del $55 \%, 46 \%$ y $41 \%$, respectivamente. Posteriormente, surgen los conceptos Cercano/a y Educación, el primero con VMT de 31 y FMG del 36\% y el segundo con un valor $\mathrm{M}$ total de 28 y un porcentaje del $33 \%$. Finalmente, hay una red de conceptos, con una distancia semántica entre 18\% y $21 \%$. Estos conceptos son: Sabio, Profesional, Persona y Autoridad. Por su parte, la riqueza semántica de la red estuvo compuesta por un total de 33 definidoras.

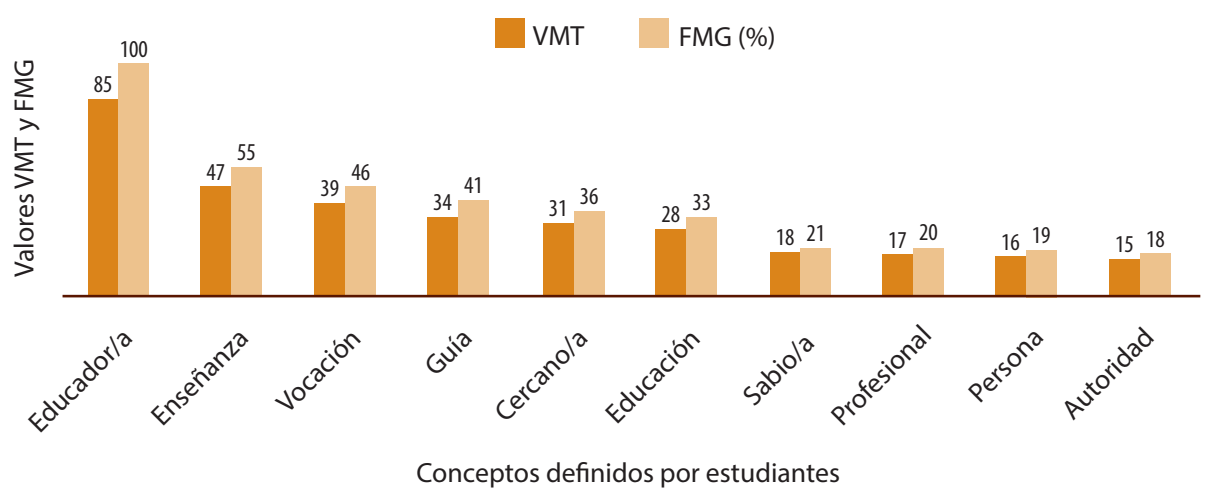

Figura 5: Conjunto SAM de las estudiantes de Educación Parvularia

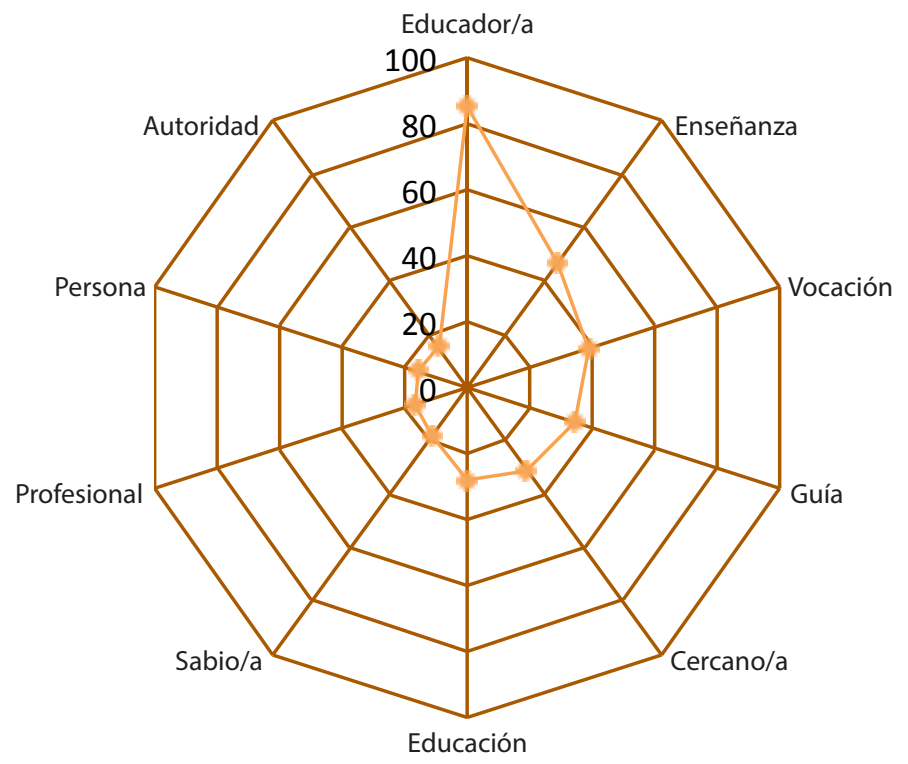

Figura 6: Núcleo de la red semántica de las estudiantes de Educación Parvularia. 
doi: http://dx.doi.org/10.15359/ree.21-1.13

URL: http://www.una.ac.cr/educare

Para las estudiantes de la Carrera de Pedagogía en Educación Especial (Figuras 7y 8) el concepto Profesor/a está constituido centralmente por la palabra Educador/a, valor M total de 181, lo que, en términos porcentuales, respecto al total de la muestra, equivale a un 100\%. Posteriormente, emergen las palabras Enseñanza (49\%) y Guía (45\%). Seguidamente, aparece el concepto de Vocación, con un VMT de 50 y un valor porcentual del $28 \%$. Inmediatamente, hay tres palabras con un peso semántico entre el $13 \%$ y el 16\%, estos conceptos son: Apoyo, Educación y Conocimiento. Por último, y con una distancia semántica cercana al 10\%, emergen el grupo de palabras: Responsabilidad, Compromiso y Profesional. La riqueza semántica de la red estuvo compuesta por un total de 27 definidoras.

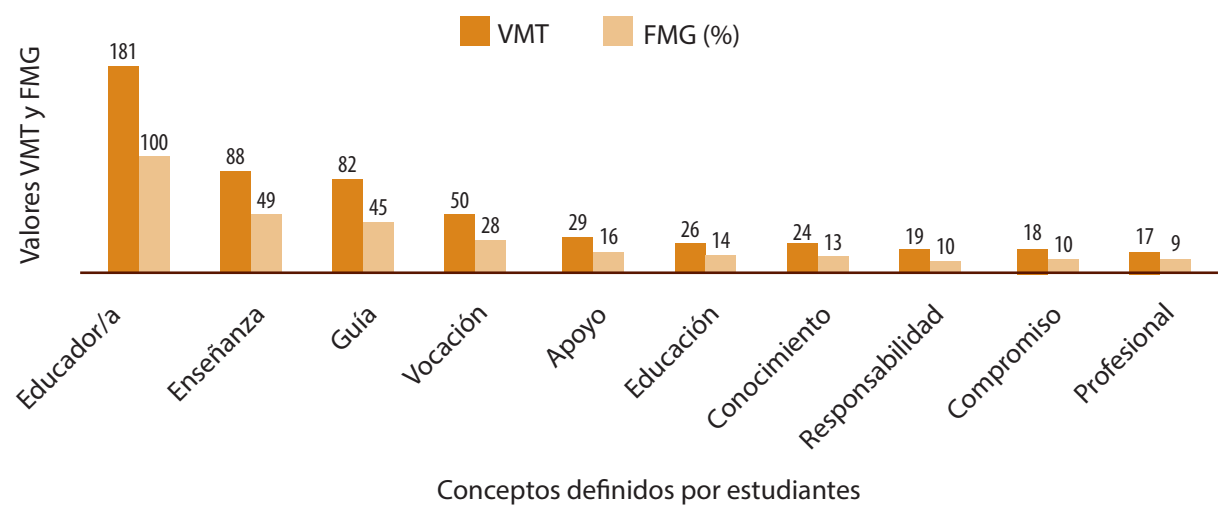

Figura 7: Conjunto SAM de los estudiantes de Pedagogía en Educación Especial.

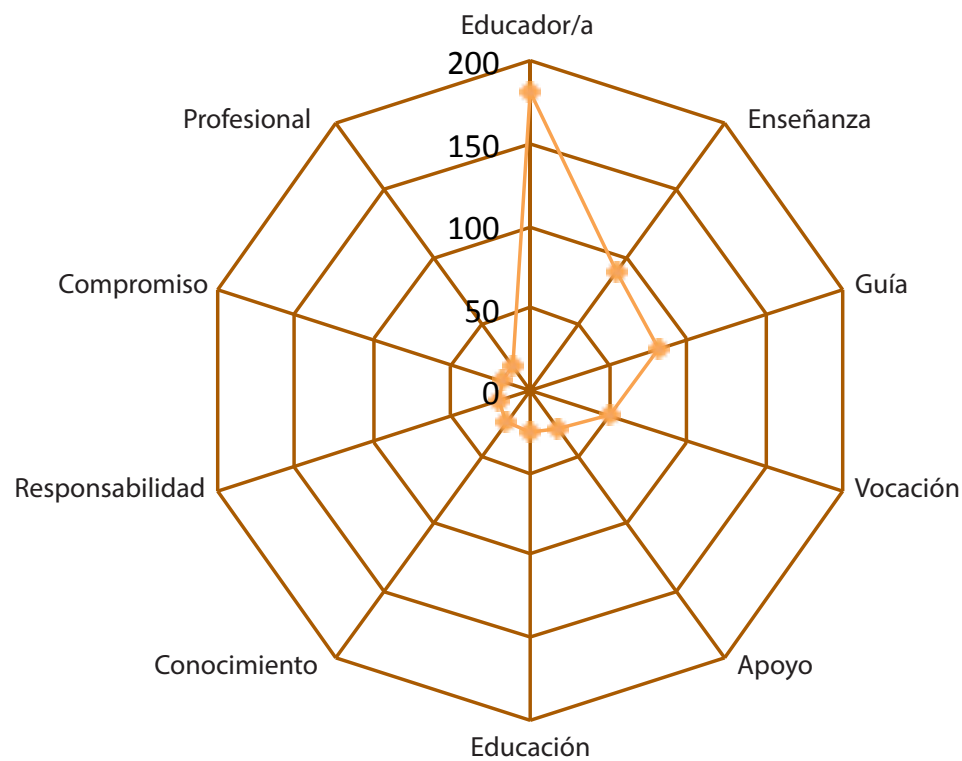

Figura 8: Núcleo de la red semántica estudiantes de Pedagogía en Educación Especial. 
doi: http://dx.doi.org/10.15359/ree.21-1.13

URL: http://www.una.ac.cr/educare

CORREO: educare@una.cr

Para el caso del alumnado de la Carrera de Pedagogía en Educación Física (ver Figuras 9 y 10) el núcleo de la red quedó representado ampliamente por el concepto Formador (VMT, de 347 y porcentaje del $100 \%$ ). También, destacan como palabras importantes: Modelo (VMT de 113 y porcentaje del 33\%), Guía (VMT de 105 y porcentaje del 30\%) y Enseñanza (VMT de 89 y FMG con porcentaje del 26). Surge también, una red de cuatro conceptos con peso semántico entre el 10\% y $15 \%$. Estos fueron: Conocimiento, Autoridad, Vocación y Profesional. Por último, emergen dos palabras con valor del $9 \%$, ellas serían: Líder y Carismático/a. Por su parte, la riqueza semántica de la red estuvo compuesta por un total de 20 definidoras.

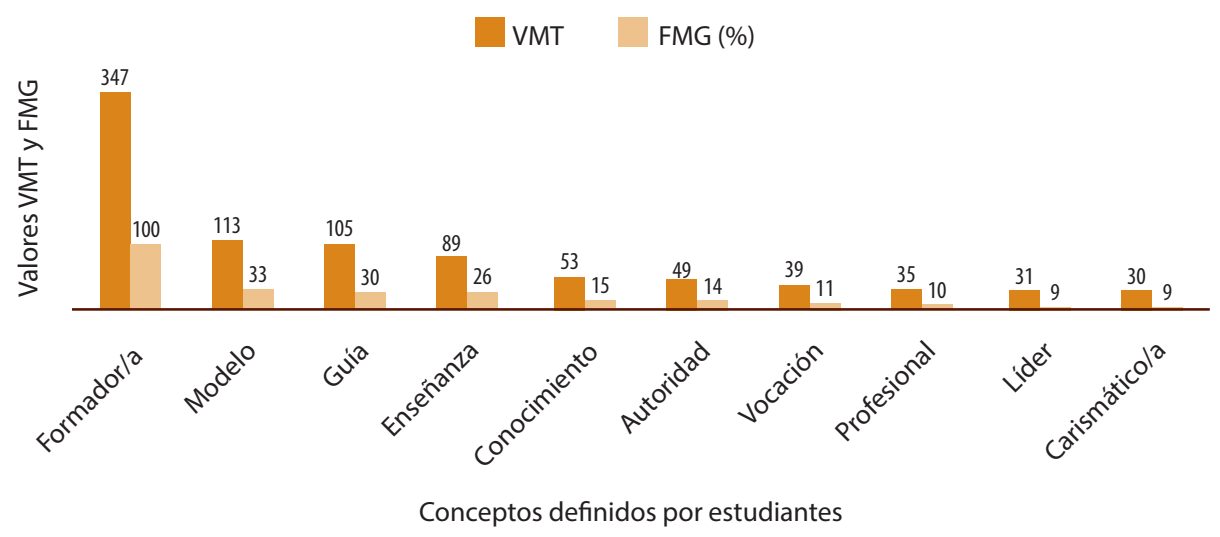

Figura 9: Conjunto SAM estudiantes de Pedagogía en Educación Física.

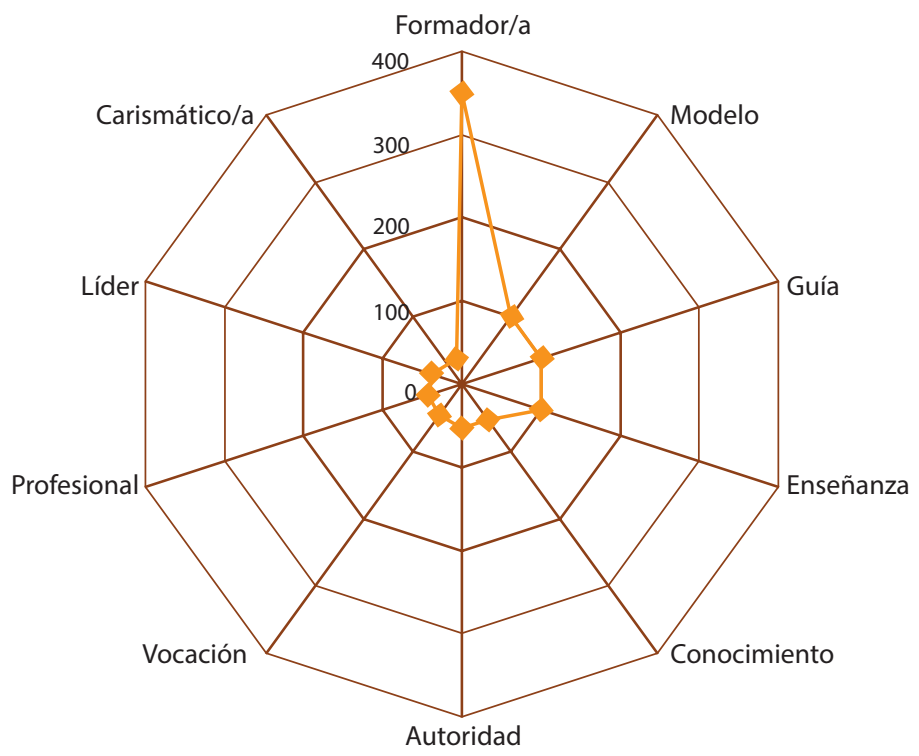

Figura 10: Núcleo de la red semántica estudiantes de Pedagogía en Educación Física. 
doi: http://dx.doi.org/10.15359/ree.21-1.13

URL: http://www.una.ac.cr/educare

Respecto de la red de significados para la Carrera de Pedagogía en Inglés, el mayor peso semántico (ver Figuras 11 y 12) es para la palabra Formador, VMT de 130 y FMG del 100\%. Posteriormente, emergen las palabras Guía (64\%) y Conocimiento (58\%). También, hay resultados significativos para los conceptos Respeto, Apoyo y Cercano/a. El primero con VMT de 47 y FMG del 36\%, segundo, 43 y FMG de 33\% y finalmente el tercero, con un valor $M$ total de 42 y un porcentaje del $32 \%$. Por último, emerge un conjunto de dos palabras con un peso semántico entre el $25 \%$ y $29 \%$. Estos conceptos son: Vocación y Enseña, quedando en último término los conceptos de Modelo y Líder con valores FMG de 18\% y 15\%, respectivamente. Cabe mencionar, que la riqueza semántica de la red estuvo compuesta por un total de 29 definidoras.

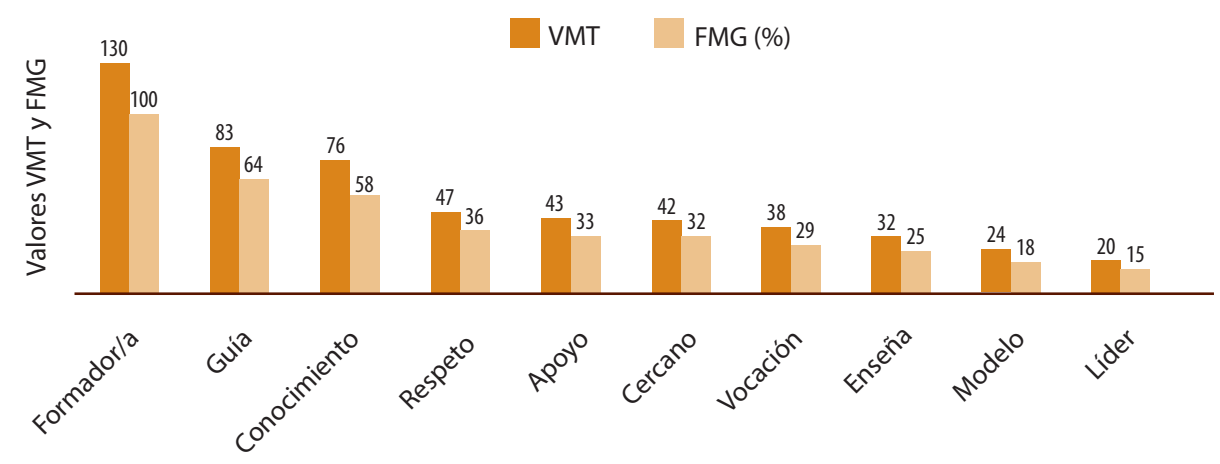

Conceptos definidos por estudiantes

Figura 11: Conjunto SAM estudiantes de Pedagogía en Inglés.

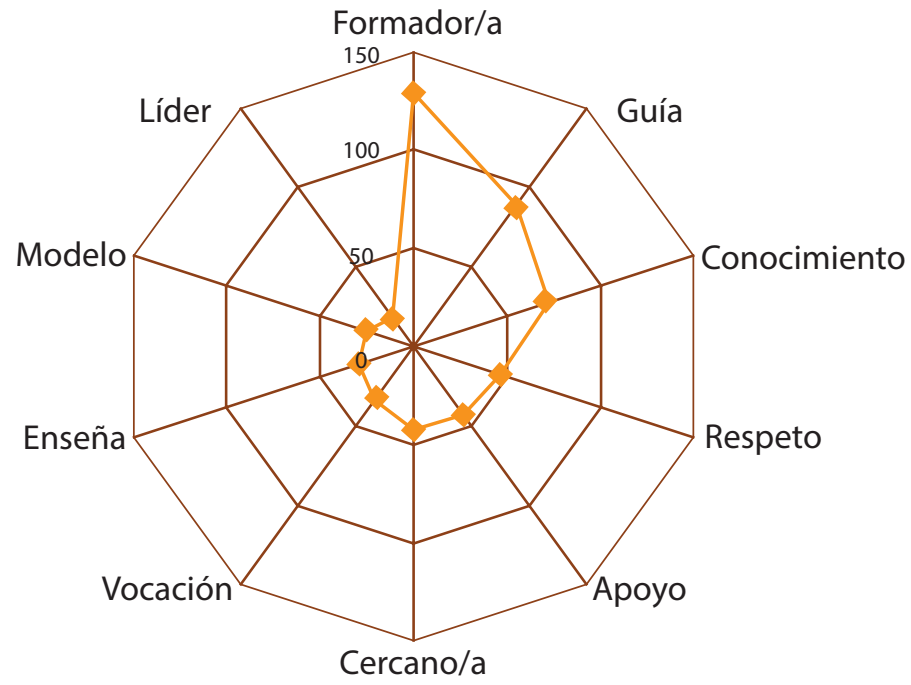

Figura 12: Núcleo de la red semántica de estudiantes de Pedagogía en Inglés. 
doi: http://dx.doi.org/10.15359/ree.21-1.13

URL: http://www.una.ac.cr/educare

CORREO: educare@una.cr

Para el estudiantado de la Carrera de Pedagogía en Lengua Castellana y Comunicación (ver Figuras 13 y 14), el núcleo del significado psicológico del concepto Profesor/a está constituido troncalmente por las palabras Formador/a (100\%) y Guía (87\%). Luego, emerge solitariamente el concepto de Conocimiento (35\%). Seguidamente, figuran las palabras Responsable (19\%) y Apoyo (16\%). Por último, y con una distancia semántica entre el $9 \%$ y $13 \%$ aparece el núcleo de conceptos: Líder, Tolerante, Vocación, Empático y Profesional. La riqueza semántica de la red estuvo compuesta por un total de 29 definidoras.

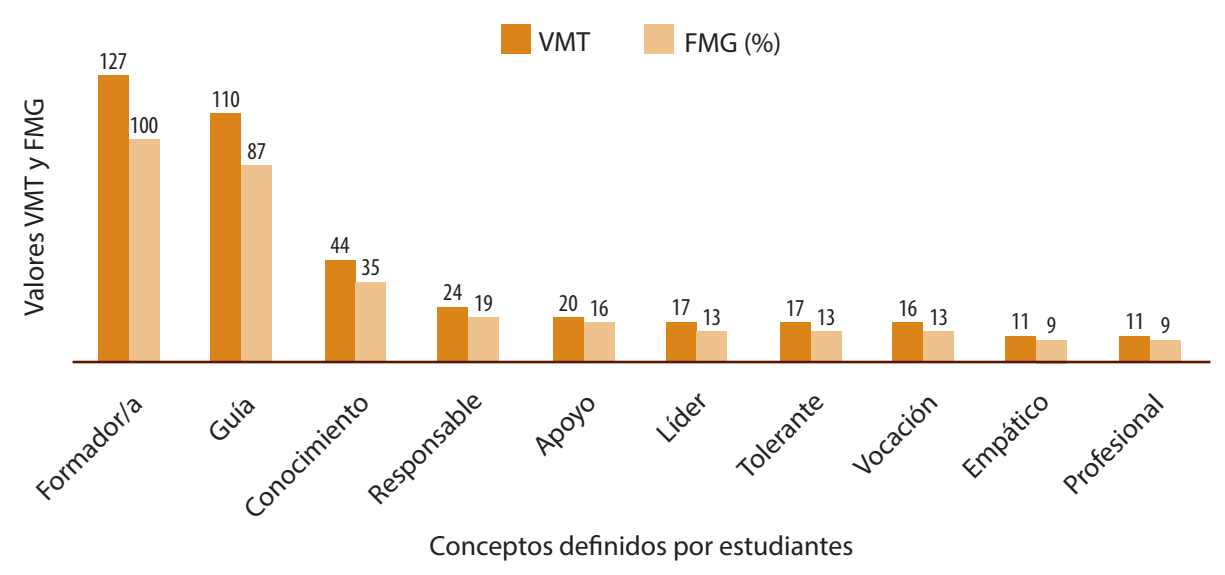

Figura 13: ConjuntoSAMestudiantes de Pedagogía en Lengua Castellana y universitarios.

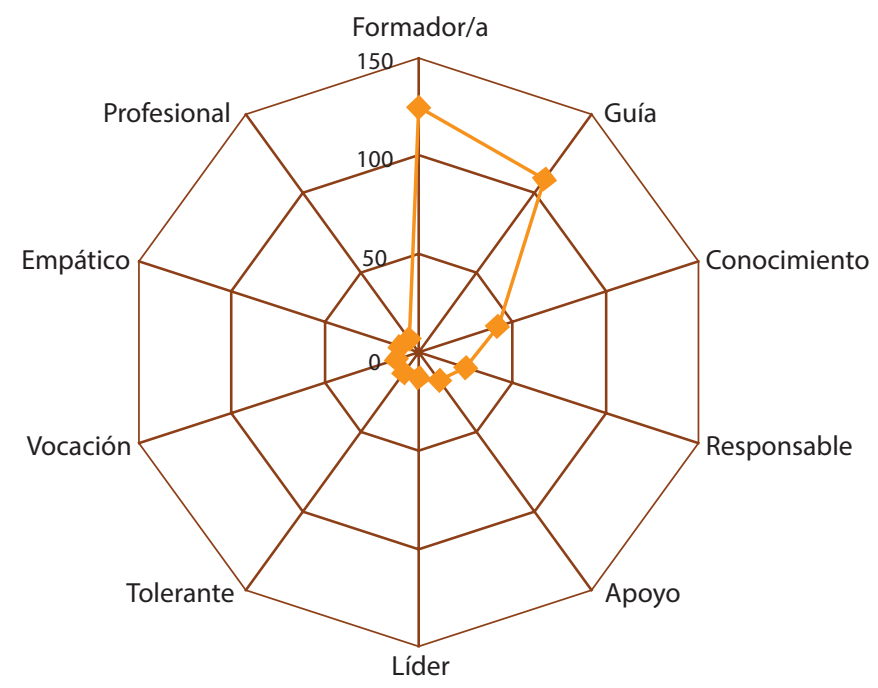

Figura 14: Núcleo de la red semántica estudiantes de Pedagogía en Lengua Castellana y Comunicación. 
doi: http://dx.doi.org/10.15359/ree.21-1.13

URL: http://www.una.ac.cr/educare

CORREO: educare@una.cr

\section{Facultad de Ciencias Básicas}

Para el alumnado de la Carrera de Pedagogía en Ciencias con mención (ver Figuras 15 y 16), el núcleo semántico de la palabra Profesor/a se inscribe hacia el concepto Formador/a (VMT de 73 y porcentaje del 100\%). También, destacan en la red conceptual las palabras Enseñanza (89\%), Guía (77\%) y Sabio/a (75\%). Posteriormente, emergen los conceptos de Apoyo (30\%), Estudiantes (27\%) y Vocación (27\%). Por último, y con una distancia semántica del 19\%, se agrupan los conceptos de Autoridad, Instructor/a y Modelo. Finalmente, la riqueza semántica de la red estuvo compuesta por un total de 27 definidoras.

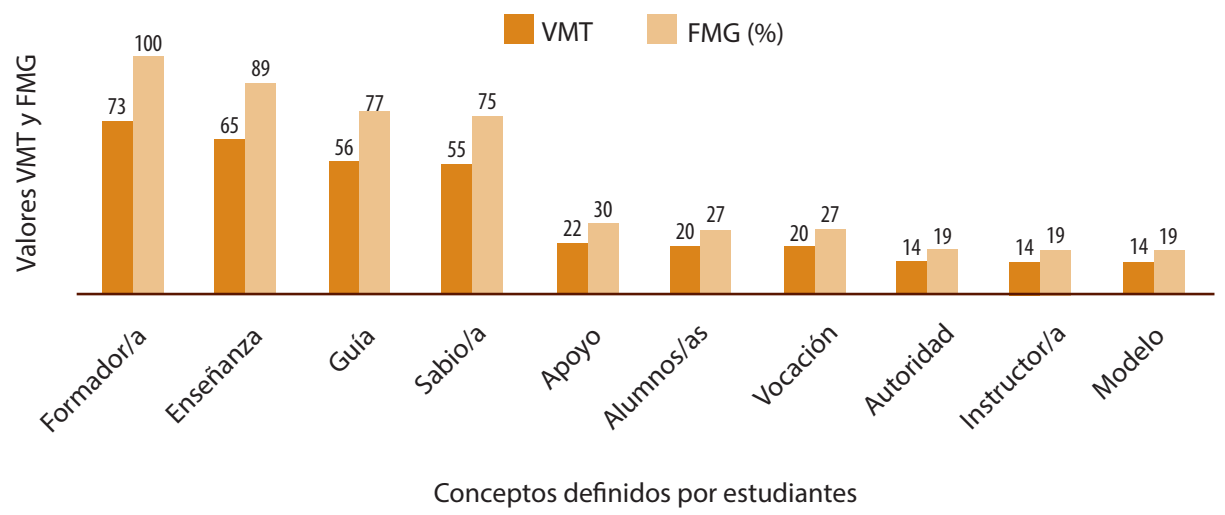

Figura 15: Conjunto SAM estudiantes de Pedagogía en Ciencias con mención.

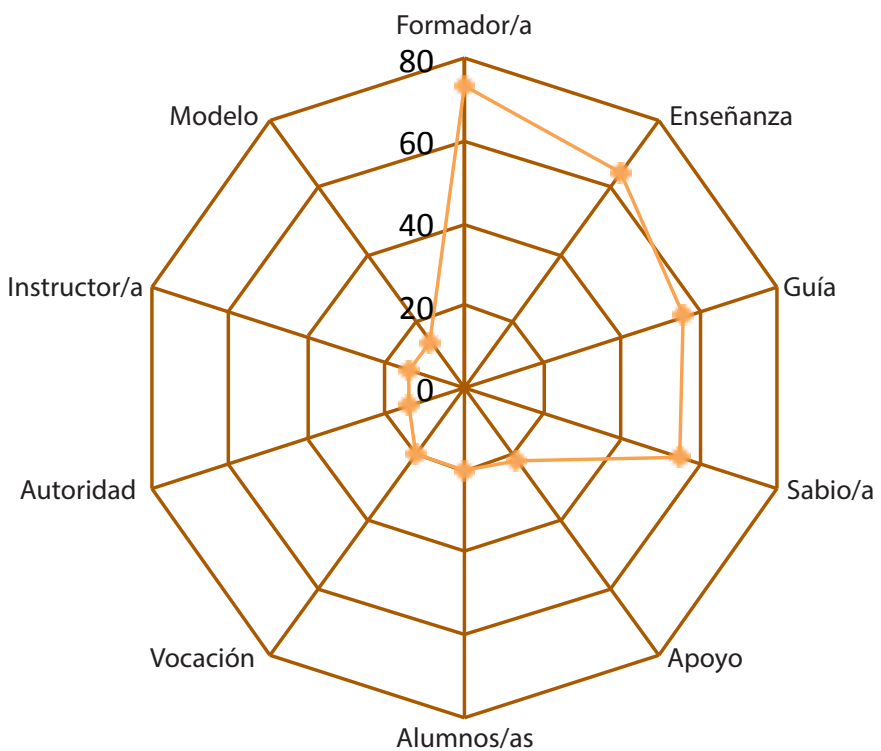

Figura 16: Núcleo de la red semántica de los estudiantes de Pedagogía en Ciencias con mención. 
doi: http://dx.doi.org/10.15359/ree.21-1.13

URL: http://www.una.ac.cr/educare

CORREO: educare@una.cr

En cuanto al concepto de Profesor/a, para el alumnado de la Carrera de Pedagogía en Matemática y Computación (ver Figuras 17 y 18), el núcleo de la red conceptual quedó representado ampliamente por la palabra Formador/a, seguido inmediatamente por el concepto Experto/a (36\%). Luego los valores descienden y aparece la palabra Enseñanza (27\%). Posteriormente, emerge un grupo de conceptos con distancias semánticas similares. Estos conceptos fueron Guía (16\%), Tolerante (14\%), Autoridad (13\%), Educación (13\%) y Vocación. Por último, y con una distancia semántica inferior al 10\%, surgen los conceptos de Apoyo y Aprendizaje. La riqueza semántica de la red estuvo compuesta por un total de 17 definidoras.

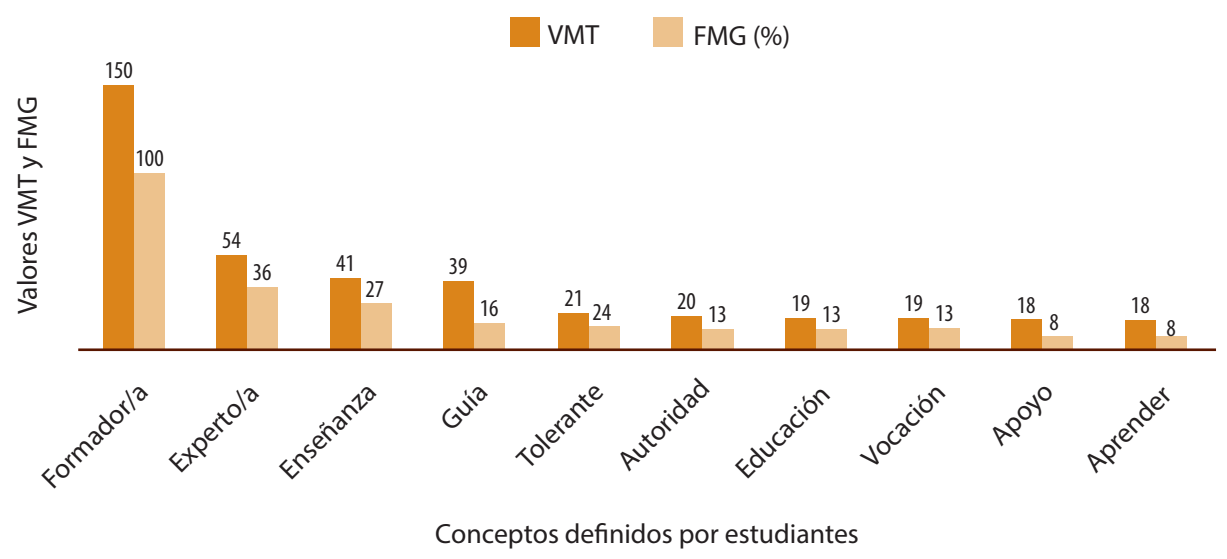

Figura 17: Conjunto SAM estudiantes de Pedagogía en Matemática y Computación.

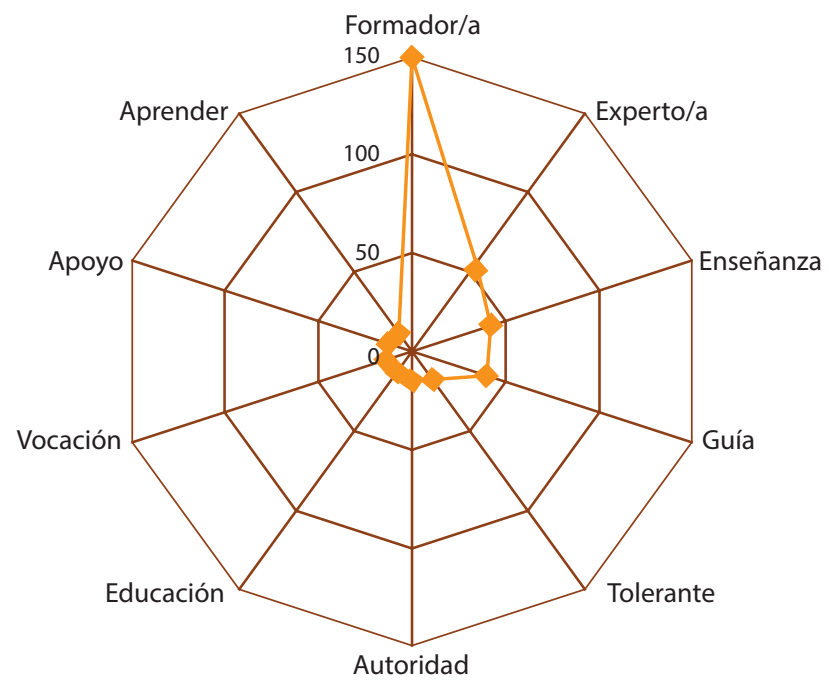

Figura 18: Núcleo de la red semántica de estudiantes de Pedagogía en Matemática y Computación. 
doi: http://dx.doi.org/10.15359/ree.21-1.13

URL: http://www.una.ac.cr/educare

CORREO: educare@una.cr

\section{Facultad de Ciencias Filosóficas y Religiosas}

Para estudiantes de la Carrera de Pedagogía en Religión y Filosofía (ver Figuras 19 y 20), el núcleo semántico de la red conceptual quedó constituido por la palabra Formador/a. Posteriormente, emergen cinco conceptos con distancias semánticas entre los rangos 32\% y $36 \%$. Estas palabras fueron: Autoridad, Vocación, Guía, e Instructor/a. Seguidamente, y con valores de distancia semántica del 23\% figuran los conceptos Justo/a, Persona, y Transforma. Finalmente, surge el concepto de Aprendizaje con un valor de distancia semántica del 18\%. La riqueza semántica de la red estuvo compuesta por un total de 20 definidoras.

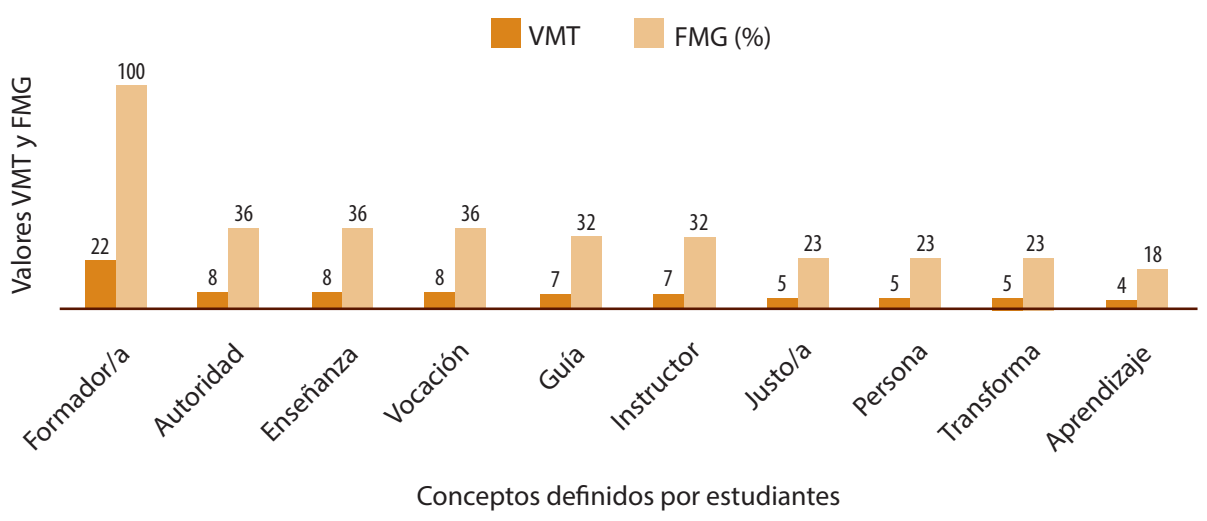

Figura 19: Conjunto SAM estudiantes de Pedagogía en Religión y Filosofía.

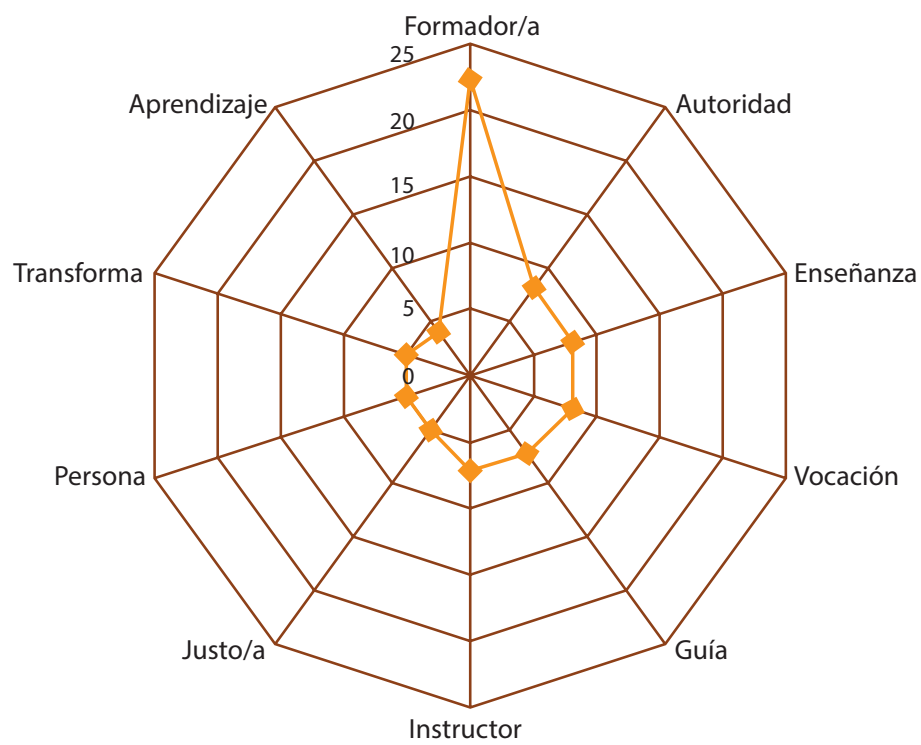

Figura 20: Núcleo de la red semántica de estudiantes de Pedagogía en Religión y Filosofía. 
doi: http://dx.doi.org/10.15359/ree.21-1.13

URL: http://www.una.ac.cr/educare

CORREO: educare@una.cr

\section{Discusión}

La mayor riqueza semántica respecto del Valor J fue para la carrera de Educación Parvularia y la red conceptual con menos definidoras fue para la carrera de Pedagogía en Matemática y Computación.

Las distancias semánticas resultantes entre las diferentes palabras que conformaron los Valores SAM fueron para el conjunto de estudiantes vinculado a las pedagogías de Enseñanza Media, con valores más homogéneos para aquellas carreras focalizadas hacia la enseñanza Preescolar y Básica.

También se visualiza, por una parte, que si bien hay elementos comunes de significado psicológico para la figura Profesor/a (en cada grupo participante), también coexisten en ellos una serie de significados claramente diferenciadores. En efecto, las redes conceptuales que construyen los grupos de estudiantes participantes varían claramente en función de la carrera pedagógica que cursan, la naturaleza que define a su especialidad y el nivel educativo al cual proyectan su quehacer pedagógico.

Para el estudiantado ser profesor o profesora de enseñanza media implica mayor manejo de saberes disciplinares respecto de estudiantes con foco en la enseñanza básica, en donde se valoran aspectos vinculados hacia lo pedagógico-didáctico y lo valórico.

Otro elemento distintivo, que marca diferencias entre los grupos de estudiantes, según carrera y nivel educativo elegido, es que los elementos conceptuales ligados a la Afectividad aparecen con más frecuencia en las carreras de prebásica y básica, que aquellas vinculadas a la formación media.

Para el común de estudiantes, independiente de la carrera a la cual pertenezcan, el Profesor/a representa la idea de Formador/a, de Maestro/a, de alguien que Guía, Educa y Lidera.

Otros núcleos figurativos nos indican que el estudiantado visualiza al Profesor/a como un sujeto Referencial, simbolizado en una red de conceptos en donde el eje troncal queda dado por palabras como Ejemplo y Modelo. En este sentido, para el alumnado de la Carrera de Pedagogía en Educación Física, este último concepto es un elemento fundamental del núcleo de la red que han definido.

Por su parte, también resulta interesante saber que, para estudiantes pertenecientes a las carreras de los niveles iniciales de formación, preescolar y básica, esta idea de Profesor/a (que Guía, Educa y Lidera) va asociada a elementos de carácter Afectivo.

Conceptos nucleares en las redes de estos grupos, como Cercanía, Amabilidad, Empatía, Compromiso y Apoyo, son claras palabras que nos revelan, de una u otra forma, las diferencias respecto de estudiantes de niveles formativos superiores. Así también queda en evidencia, en un trabajo llevado a cabo por Cabalín, Navarro, Zamora y San Martín (2010), al indicar que el 
doi: http://dx.doi.org/10.15359/ree.21-1.13

URL: http://www.una.ac.cr/educare

CORREO: educare@una.cr

estudiantado expresa características valóricas de sus docentes por sobre las actitudes relacionadas con temáticas vinculadas a saberes conceptuales, denotando de esta manera la importancia que tiene para el estudiantado el aspecto actitudinal y valórico del personal docente.

Otra familia conceptual que resulta importante destacar y que es común en cada una de las redes estudiadas, define al Profesor/a como una Autoridad a cuyo nodo conceptual se suman otros elementos semánticos importantes como Respeto y Disciplina. En este sentido, los datos coinciden con recientes investigaciones llevadas a cabo por Alarcón, Díaz, Tagle, Ramos y Quintana (2014), en donde un grupo de estudiantes de pedagogía ve al profesorado como una figura de Autoridad Superior.

Un dato que nos parece interesante de analizar, desde la red conceptual definida por las alumnas de la carrera de Educación Parvularia, es que ampliamente el significado psicológico del concepto queda simbolizado en la idea de Educador y Educadora. Este proceso identitario de las educadoras de párvulos supone en la práctica una organización reciproca entre lo individual y lo colectivo, cuyo componentes psíquicos y sociales se estructuran armónicamente (Vera et al., 2005), se le atribuyen, de este modo, al concepto significados que, en el caso de Chile, las define y caracteriza tradicionalmente. Es lo que Tardif (2010) denomina un saber social, que se construye en interacciones colectivas con diversas fuentes de conocimiento.

También, resulta revelador indicar que, dentro de la red conceptual definida por este grupo de estudiantes, surge una palabra que no aparece como concepto nodal en otras carreras (excepto en alumnado de Pedagogía en Religión y Filosofía), nos referimos al concepto Persona. Su aparición, quizás, se explica a partir de los marcos figurativos de lo que socialmente implica formar infantes, y de las características del proceso educativo llevado a cabo. Un proceso que implica desarrollar globalmente todas las capacidades del niño. Así, queda de manifiesto en Las bases curriculares de la educación parvularia (Gobierno de Chile, Ministerio de Educación, 2005) que es apremiante favorecer en los párvulos "aprendizajes oportunos y pertinentes, [atendiendo] a sus características, necesidades e intereses [particulares, a objeto de fortalecer] sus potencialidades para un desarrollo pleno y armónico" (p. 14).

Para el caso de las estudiantes de Pedagogía en Educación Especial, la red de significados arrojó un concepto, que si bien desde el punto de vista de la distancia semántica con el núcleo marca clara diferencias, es un concepto que solo surge en la red de estas estudiantes. Nos referimos a la palabra Compromiso. Claramente la construcción simbólica de la figura Profesor/a, por parte de este colectivo, está cargada de significados psicológicos, que implican un deber ser que va más allá de los supuestos materiales e instrumentales que caracterizan su formación profesional. La estructuración de estas representaciones implica, para las estudiantes, la conformación de dimensiones de contenido compuestas de actitudes, imágenes, creencias, conocimientos y opiniones (Vera et al., 2005), que a la larga le dan valor y sentido a lo que deseamos hacer en nuestra vida profesional futura. 
doi: http://dx.doi.org/10.15359/ree.21-1.13

URL: http://www.una.ac.cr/educare

CORREO: educare@una.cr

Para la gran mayoría de estudiantes de carreras con foco hacia la Enseñanza Media, palabras como: Conocimiento, Sabiduría, Erudito/a, Inteligente y Sabio/a, son redes de significado trascendentales en la configuración de su identidad profesional. Claramente, en este caso, el estudiantado revela la trascendencia figurativa que tiene su futura profesión en la conformación de los aspectos de carácter cognitivo en la formación de los sujetos. Esto último, es aún más diferenciador, para el caso de alumnado de Pedagogía en Matemática y Computación, de entre sus redes surgen significados que vinculan la imagen de Profesor/a a elementos simbólicos denotados en una fuerte idea de Experto/a. Por ello, quizás, tampoco resulte sorprendente que, dentro de la red conceptual definida por estudiantes de la Carrera de Pedagogía en Ciencias, surgiera del mismo modo asociado a la figura de Profesor/a el concepto de Instructor/a.

Por último, otras similitudes, en torno a núcleos de palabras comunes, es la referida al concepto de Vocación. Para la gran mayoría de estudiantes, indistintamente de la carrera a la que pertenezcan, este es un concepto con un peso semántico importante. Hipotéticamente, podemos decir que, para los sujetos del estudio, ser maestro o maestra implica poseer Vocación. Lo anterior, dado que involucra no solo transmitir conocimientos, sino también ser un pilar fundamental para el desarrollo intelectual y cultural de los grupos de estudiantes... un Líder, un Orientador/a, un Facilitador/a, un Constructor/a, alguien quien Motiva constantemente, Apoya y es capaz de ponerse en el lugar de las otras personas (Empático/a). Así también lo refieren en sus investigaciones Alarcón et al. (2014). El maestro o maestra es una columna que sostiene; una mano amiga en quien confiar; un padre y madre; un sujeto reparador, cuidador, líder; un parte de un todo: héroe.

En relación con los escenarios desde donde se forman al estudiantado, el análisis de las redes conceptuales surgidas, en general, nos revela que en aquellas facultades en donde se estudia para ser docente de enseñanza media existe una mayor valoración del conocimiento, la sabiduría y la formación disciplinar. La misma valoración conceptual sucede con las carreras de este nivel al interior de la Facultad de Ciencias de la Educación. Lo anterior, quizás, se fundamenta desde los paradigmas sobre los cuales se ha construido la formación de docentes de educación media en el país, siempre desde una lógica fuertemente disciplinar y desde modelos pedagógicos de transmisión-recepción.

\section{Conclusiones}

De acuerdo con los resultados arrojados en esta investigación, podemos concluir lo siguiente:

Hay elementos comunes de significado en cada grupo participante. Independiente de la carrera a la cual pertenezcan, el Profesor o Profesora representa la idea de Formador/a, de Maestro/a y Guía. Sin embargo, coexisten una serie de significados visiblemente diferenciadores. 
doi: http://dx.doi.org/10.15359/ree.21-1.13

URL: http://www.una.ac.cr/educare

CORREO: educare@una.cr

Las redes conceptuales constituidas varían claramente en función de la carrera que cursan, la naturaleza que define a su especialidad y el nivel educativo al cual proyectan su quehacer laboral.

Para los estudiantes de carreras pedagógicas ligadas a la enseñanza media ser docente implica mayor manejo de los saberes disciplinares y una enseñanza más instructiva... hay una mayor valoración del conocimiento, la autoridad, la disciplina, el respeto y el modelaje. En cambio, estudiantes con foco hacia la enseñanza básica y preescolar valoran más aspectos vinculados hacia la mediación, la motivación extrínseca y los saberes pedagógicos.

Otro elemento distintivo entre los grupos de estudiantes, según la carrera y el nivel educativo, es que los elementos conceptuales ligados a la afectividad y los temas valóricos aparecen con más frecuencia en las carreras de prebásica y básica, que en aquellas vinculadas a la formación media.

Para el estudiantado de las carreras de preescolar y educación diferencial, la construcción del significado de la figura Profesor/a, está cargada de elementos semánticos que implican un deber ser que va más allá de los supuestos materiales e instrumentales que caracterizan su formación profesional.

Por otro lado, para la gran mayoría del estudiantado, indistintamente de la carrera a la cual se ligan, ser docente admite tener Vocación. No solo implica transmitir conocimientos, sino también, ser un mediador en el desarrollo emocional e intelectual de los sujetos.

Finalmente, cabe indicar que el desafío que enfrentan las universidades que forman profesorados guarda relación con la capacidad de estas para innovar respecto de sus procesos formativos.

Nuestros sistemas escolares necesitan, cada vez más, docentes con altas capacidades disciplinares y pedagógicas con el objetivo de formar un colectivo de estudiantes que deben enfrentar una sociedad compleja, diversa y cambiante. Poder identificar estos significados psicológicos que representa la figura docente para un iniciado en pedagogía es clave. Del mismo modo, simboliza todo un desafío institucional.

Por último, estamos convencidos que este trabajo no termina acá, seguir indagando en los significados que estudiantes de pedagogía construyen en torno a su propio quehacer personal y profesional constituye un desafío en la FID, sobre todo si somos capaces de vislumbrar si estos significados son mantenidos o bien transformados durante los años que dura su proceso formativo, pues, no debemos olvidar, que el pensamiento de cada docente y en concreto sus ideas, creencias y modelos, guían su labor educativa y condicionan significativamente los acontecimientos que ocurrirán en el aula. 
doi: http://dx.doi.org/10.15359/ree.21-1.13

URL: http://www.una.ac.cr/educare

CORREO: educare@una.cr

\section{Referencias}

Alarcón, P., Díaz, C. Tagle, T., Ramos, L. y Quintana, M. (2014). Conceptualizaciones metafóricas sobre el rol del profesor en estudiantes de pedagogía. Estudios Pedagógicos, 2, 27-44. doi: https://doi.org/10.4067/S0718-07052014000300002

Anderson, J. R. (1983). A spreading activation theory of memory. Journal of Verbal Learning and Verbal Behavior, 22(3), 261-295. doi: https://doi.org/10.1016/S0022-5371(83)90201-3

Ausubel, D. (2009). Adquisición y retención del conocimiento. Una perspectiva cognitiva. Barcelona: Paidós.

Bourdieu, P (2012). La distinción. Criterio y bases sociales del gusto. Madrid: Taurus.

Cabalín, D., Navarro, N., Zamora, J. y San Martín, S. (2010). Concepción de estudiantes y docentes del "buen profesor universitario". Facultad de Medicina de la Universidad de La Frontera. International Journal Morphology, 28(1), 283-290. doi: https://doi.org/10.4067/S0717$\underline{95022010000100042}$

Chevallard, Y. (2000). La transposición didáctica. Del saber sabio al saber enseñado. Buenos aires: Aique.

Collins, A. M. y Loftus, E. F. (1975). A spreading-activation model of semantic processing. Psychological Review, 82(6), 407-428. doi: https://doi.org/10.1037/0033-295X.82.6.407

Figueroa, J. (1980). Sobre la teoría general de las redes semánticas. Facultad de Psicología de la Universidad Nacional Autónoma de México. Manuscrito inédito.

García-Carmona, A., Vázquez, Á., y Manassero, M. A. (2011). Estado actual y perspectivas de la enseñanza de la naturaleza de la ciencia: Una revisión de las creencias y obstáculos del profesorado. Enseñanza de las Ciencias, 28(3), 403- 412. Recuperado de http://www.raco. cat/index.php/Ensenanza/article/viewFile/247899/353583

García-Villanueva, J., De la Rosa-Acosta, A. y Castillo-Valdés, J. S. (2012). Violencia: Análisis de su conceptualización en jóvenes estudiantes de bachillerato. Revista Latinoamericana de Ciencias Sociales, Niñez y Juventud, 10(1), 495-512. Recuperado de http://www.scielo.org. co/pdf/rlcs/v10n1/v10n1a32.pdf

Gobierno de Chile. Ministerio de Educación. (2005). Bases curriculares de la educación parvularia. Santiago de Chile: Autor. Recuperado de http://www.docentemas.cl/docs/2014/ Educacion \%20Parvularia/Bases\%20curriculares\%20de\%20la\%20Educacion $\% 20$ Parvularia.pdf 
doi: http://dx.doi.org/10.15359/ree.21-1.13

URL: http://www.una.ac.cr/educare

CORREO: educare@una.cr

Hofstadter, D. R. (1982). Can inspiration be mechanized? Scientific American, 247(3), 18-31. doi: https://doi.org/10.1038/scientificamerican1282-18

Marcelo, C. (1999). Formación del profesorado para el cambio educativo. Barcelona: EUB.

Marshall, S. P. (1995). Schemas in problem solving. Cambridge: Cambridge University Press. doi: https://doi.org/10.1017/CBO9780511527890

Maturana, H. y Varela, F. (2003). El árbol del conocimiento. Las bases biológicas del entendimiento humano. Buenos Aires: Lumen.

McKoon, G. y Ratcliff, R. (1986). Inferences about predictable events. Journal of experimental Psychology:learning, Memory and cognition, 12(1), 82-91.doi: https://doi.org/10.1037/0278$\underline{7393.12 .1 .82}$

Minsky, M. (1975). A framework for representing knowledge. En P.H. Winston (Ed.), The psychology of computer vision (pp. 211-277). New York: McGraw-Hill.

Morin, E. (2007). Introducción al pensamiento complejo (9a ed.) Barcelona: Gedisa.

Norman, D. A. (1987). Perspectivas de la ciencia cognitiva. Argentina: Paidós.

Novak, J. D. (1990). Teoría y práctica de la educación. Madrid: Alianza.

Ormrod, J. E. (2010). Aprendizaje humano. Madrid: Pearson Educación.

Pattee, H. H. (1973). Hierarchy theory. The challenge of complex systems. Nueva York: George Braziller.

Piaget, J. e Inhelder, B. (2007). Psicología del niño (17a ed.). Madrid: Morata.

Quillian, M. R. (1968). Semantic memory. En M, Minsky (Ed.), Semantic information processing (pp. 227-270). Cambridge, Mass: MIT Press.

Quillian, M. R. (1969). The teacheable languaje comprehender. A simulation program and theory of language. Comunications of the association for Computing Machinery, 12(8), 459-476.

Rips, L. J., Shoben, E. J. y Smith, E. E. (1973). Semantic distance and the verification of semantic relations. Journal of Verbal Learning and Verbal Behavior, 12(1), 1-20. doi: https://doi. org/10.1016/S0022-5371(73)80056-8

Rumelhart, D. E. (1975). Notes on a schema for stories. En D. G. Bobrow y A. Collins (Eds.), Representation and understanding: Studies in cognitive science (pp. 211-236). Michigan: Academic Pres. doi: https://doi.org/10.1016/b978-0-12-108550-6.50013-6 
doi: http://dx.doi.org/10.15359/ree.21-1.13

URL: http://www.una.ac.cr/educare

CORREO: educare@una.cr

Rumelhart, D. E. (1984). Schemata: The building blocks of cognition. En J. T. Guthrie (Ed.), Comprehension and teaching: Research reviews (pp. 3-26). Newark, DE: International Reading Association.

Tardif, M. (2010). Los saberes del docente y su desarrollo profesional ( $3^{\mathrm{a}}$ ed.). Madrid: Narcea.

Valdez, J. L. (1998). Las redes semánticas naturales, usos y aplicaciones en psicología social. México: Universidad Autónoma del Estado de México.

Vera, J. Á., Pimentel C. E. y Batista, F. J. (2005). Redes semánticas: Aspectos teóricos, técnicos, metodológicos y analíticos. Ra Ximhai,1(3), 439-451. Recuperado de http://www.revistas. unam.mx/index.php/rxm/article/view/6845/6365

Vygotski, L. S. (2009). El desarrollo de los procesos psicológicos superiores. Barcelona: Crítica.

Winograd, T. (1975). Frame representations and the declarative/procedural controversy. En D. G. Bobrow y A.M. Collins (Eds.), Representation and understanding: Studies in cognitive science (pp. 185-210). San Diego: Academic Press. 